$\begin{array}{ll} & \text { Etnográfica } \\ \text { etnográfica } & \text { Revista do Centro em Rede de Investigação em }\end{array}$

Antropologia

vol. $26(1) \mid 2022$

Vol. $26(1)$

\title{
Renegociar a comunidade e disputar territórios: posse e propriedade nas terras comunitárias na região do lago Niassa
}

Renegotiating the community and disputing territories: land tenure and ownership in the community lands in the lake Niassa region

\section{Elísio Jossias}

\section{OpenEdition}

\section{Journals}

\section{Edição electrónica}

URL: https://journals.openedition.org/etnografica/11017

DOI: 10.4000/etnografica. 11017

ISSN: 2182-2891

\section{Editora}

Centro em Rede de Investigação em Antropologia

\section{Edição impressa}

Paginação: 5-27

ISSN: 0873-6561

\section{Refêrencia eletrónica}

Elísio Jossias, «Renegociar a comunidade e disputar territórios: posse e propriedade nas terras

comunitárias na região do lago Niassa», Etnográfica [Online], vol. 26 (1) | 2022, posto online no dia 25 fevereiro 2022, consultado o 30 junho 2022. URL: http://journals.openedition.org/etnografica/11017 ; DOI: https://doi.org/10.4000/etnografica. 11017

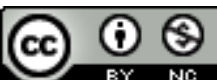

Etnográfica is licensed under a Creative Commons Attribution-NonCommercial 4.0 International License. 


\section{Renegociar a comunidade e disputar territórios: posse e propriedade nas terras comunitárias na região do lago Niassa}

Elísio Jossias

O presente artigo parte da experiência de delimitação de terras comunitárias, em Cóbuè, província do Niassa, para analisar a interface entre as lideranças tradicionais e os sistemas costumeiros de terras, em Moçambique, enquadrando os debates sobre terra e território, posse e propriedade da terra, bem como os encontros com a história territorial, os impactos das transformações, da legislação e da demanda por terras. O material etnográfico, que consta do artigo, resulta de cerca de dez meses de trabalho de campo, entre 2012 e 2015 , e ajuda a reavaliar a noção de posse comunitária e o enquadramento dos sistemas costumeiros da terra, ao conceber o território enquanto espaço político.

PALAVRAS-CHAVE: terras comunitárias, sistemas costumeiros de terras, chefes tradicionais, posse e propriedade da terra, Moçambique.

Renegotiating the community and disputing territories: land tenure and ownership in the community lands in the lake Niassa region - This paper builds on the experience of implementing community land delimitation in Cóbuè, Niassa province, between 2012 and 2015, and analyses the interface between traditional leaders and customary land systems in Mozambique. The ethnographic material in this paper helps to frame the debates on land and territory, land tenure and ownership, as well as the encounters with territorial history, the impacts of transformations, legislation and demand for land. The paper contributes to the reassessment of the notion of community ownership and the framing of customary land systems when conceiving the territory as a political space.

KEYWORDS: community land, customary land systems, traditional chiefs, land tenure and ownership, Mozambique.

JOSSIAS, Elísio (ejossias@gmail.com) - Departamento de Arqueologia e Antropologia, Universidade Eduardo Mondlane, Maputo/Moçambique. Investigador visitante, School for Global Studies, Gothenburg University, Suécia. 


\section{INTRODUÇÃO}

“Tentando recuar na história, diz-se que os nossos antepassados vieram até aqui em busca de terras para fixar as suas residências. Todos vinham como parte da mesma família. Naquela altura não existia uma divisão tão exata das chefias. As chefias surgiram quando numa família passou a existir alguém mais forte que vencia os conflitos e que se impunha na resolução de problemas. As chefaturas surgem a partir desse momento: surgiu o dirigente da aldeia e as primeiras pessoas que chegaram ao território formaram a mesma linhagem. Os antepassados é que garantiram essa linhagem. Quando aqui chegaram dividiram as terras por igual e todos cultivavam" [conversa com Mzama; Cóbuè, abril de 2015].

Em agosto de 2012, quando cheguei pela primeira vez na região do lago Niassa, no norte de Moçambique, para iniciar o trabalho de campo, haviam passado cerca de cinco anos desde a delimitação de 16 territórios comunitários, ${ }^{1}$ em representação de igual número de chefes tradicionais, entre eles régulos e nduna da região. ${ }^{2}$

Esta delimitação fez-se num contexto de construção, em finais da década de 1990, de um empreendimento turístico luxuoso, que tinha a pretensão de introduzir práticas de conservação da biodiversidade. Foram então definidos e demarcados os limites de uma área de conservação comunitária denominada Manda Wilderness, gerida pela associação Umoji e por uma outra instituição filantrópica controlada pelo empreendimento turístico, ${ }^{3}$ denominada Manda Wilderness Community Trust. As áreas demarcadas para o projeto conservacionista localizam-se numa região dominada por dois principais chefes tradicionais (régulos), régulo Mataka da comunidade de Mataka e o régulo Chiteji da Comunidade de Chigoma. A estes juntam-se outros quatro régulos e respetivos chefes menores (nduna).

A delimitação foi viabilizada pela atual Lei de Terras (Lei n. ${ }^{\circ}$ 19/97, de 1 de outubro), que consagrou que normas e práticas costumeiras seriam dimensões essenciais para as comunidades rurais enquanto o garante da regulação do acesso, posse e uso da terra (Myers 1994; West e Myers 1992, 1996; Negrão 2002; De Wit e Norfolk 2010).

A integração dos sistemas costumeiros na legislação baseou-se em evidências sobre o papel ativo dos chefes tradicionais na gestão de mais de $90 \%$ das terras

I Mbweca, Mandambuzi, Manda-Litanda, Chisingo, Lukambo-Luwinga, Nkondezi, Matepwe, Magaxi, Uchessi, Chigoma, Mataka, Chikaya, Khango, Utonga, Namisse e Mala.

2 Designação adoptada no tempo colonial. Pelas classificações criadas no ano 2000 (Decreto n. ${ }^{\circ}$ 15/2000, de 20 de junho), o régulo é autoridade comunitária de primeiro escalão.

3 Em língua CiNyanja, umoji significa "união", "estamos juntos”, pode ser compreendido também como entreajuda. 
e dos recursos naturais (Tanner 2002; Negrão 2002) e foi encarada como um mecanismo para garantir a segurança da posse da terra, a resolução de conflitos e a necessidade de a terra contribuir para o desenvolvimento (West 1992; Tanner 2002; Negrão 2008). ${ }^{4}$ Para Potier (2005), este olhar sobre os sistemas costumeiros representa uma abordagem evolucionista assente no discurso da modernização introduzido pelos regimes coloniais. Este discurso acompanha a atualidade das reformas fundiárias e agrárias lideradas pelo Banco Mundial no contexto africano.

De facto, a aprovação desta Lei de Terras enquadra-se no processo de reformas da economia moçambicana, iniciado na década de 1980, e marcado pela introdução de uma economia virada para o mercado, a entrada do setor privado, a adesão ao FMI e ao Banco Mundial (Bowen 2000; Wuyts 2001). O efeito imediato deste processo foi a ligação entre a terra e os ideais desenvolvimentistas com o seu discurso de modernização. O modelo evolucionista referido por Potier (2005) está igualmente patente na definição das instituições costumeiras como modelos exclusivos das áreas rurais (West e Myers 1996; Myers 1994; Negrão 2008), uma diferenciação com o meio urbano, confirmando assim o que Mamdani (1996) apelidou continuação do estado bifurcado colonial.

$\mathrm{Na}$ década de 1990 surgiram propostas alternativas ao modelo neoliberal de reforma fundiária e agrária do Banco Mundial, conforme os casos de Ranger (1993) e Bruce (1993), que sugerem a distinção entre reformas agrárias e reformas fundiárias. Autores como Geschiere (2004, 2009), Geschiere e Nyamnjoh (2000) e Chauveau e Richards (2008) rejeitaram a ideia de coletividade e acesso generalizado à terra em África, que então parecia emergir nas mesmas propostas, sobretudo na abordagem sobre os sistemas costumeiros da terra. Pelo contrário, e a partir de um olhar historicista, estes autores sugerem que os sistemas costumeiros da terra devem ser analisados considerando que são flexíveis, ambíguos e maleáveis.

Ao longo dos cerca de 25 anos de implementação daquela lei, são várias as vozes que criticam as práticas de delimitação de terras comunitárias. Em Niassa, por exemplo, Åkesson, Calengo e Tanner (2008) criticam a delimitação dos territórios com base nos chefes tradicionais, por considerarem que confunde os modelos de governação territorial com as noções de posse comunitária de terra. A partir destas críticas, concordo com Carola Lentz (2006: 38), quando afirma que os africanos há muito que incorporaram aspetos dos direitos sobre a terra introduzidos pela administração colonial na sua conceção de tradição. Os aspectos apontados por estas críticas constituem mais

4 A Política Nacional de Terras (Resolução n. ${ }^{\circ}$ 10/95, de 17 de outubro) e a Lei de Terras (Lei n. ${ }^{\circ}$ 19/97, de 1 de outubro) enfatizam o lugar da terra na promoção do desenvolvimento, ao destacar aspetos como aumento da produção e a promoção do investimento privado. 
uma prova de que de facto é impraticável supor a distinção entre os modelos de organização social, os sistemas costumeiros e a própria definição de comunidade.

Neste artigo sigo o argumento da flexibilidade, maleabilidade e negociabilidade dos sistemas costumeiros da terra, para pensar os territórios das comunidades rurais em Moçambique integrando processos de territorialização passados e presentes. Do mesmo modo, analiso as normas e práticas costumeiras, como resultado de intensas negociações envolvendo processos de territorialização de longa duração. Com esta abordagem, analiso a natureza dos conflitos que se desencadearam momentos após a delimitação das terras comunitárias nesta região de Cóbuè, em torno das hierarquias entre os chefes tradicionais e respetivos territórios, bem como a forma como se manifesta a posse e propriedade da terra nesta região.

A delimitação de terras comunitárias remete-nos ao debate sobre a centralidade ou não dos chefes tradicionais na questão da terra em África, presente na antropologia (cf. Gluckman 1944; Bohannan 1973 [1963]; Potier 2005; Cousins 2008; Peters 2009; Lentz 2013), onde tem vindo a ser demostrada a necessidade de se desligar, analiticamente, os chefes tradicionais dos sistemas costumeiros de terras e remeter esta conceção às formas de atuação colonial (cf. Cousins 2008).

A epígrafe é um exemplo que destaca o lugar do debate e confrontação de narrativas históricas territoriais na legitimação dos estatutos e hierarquias dos chefes tradicionais e seus territórios, que se liga à identificação dos primeiros ocupantes dos lugares na paisagem, uma condição alimentada pela integração de temporalidades e historicidades diversas. Neste artigo mostro como este princípio legitima o território e as reivindicações da posse e propriedade dos seus habitantes, ao propor a análise dos sistemas costumeiros a partir do seu dinamismo, reconhecendo as historicidades dos processos de sua constituição, valorizando as experiências vividas e integrando dimensões transformativas de longo termo (Viegas 2007).

O artigo contribui para o debate sobre a terra em Moçambique, ao sugerir o uso do conceito de propriedade para responder a dois desafios: (i) a tendência de analisar o acesso, a posse, uso e segurança da terra com base no imperativo legal de a terra ser propriedade exclusiva do Estado em Moçambique (cf. Hanlon 2004; Mosca 201 1; Serra e Carrilho 2013; Mandamule 2017); e (ii) a dificuldade que a antropologia demonstrou ao longo dos séculos na utilização deste mesmo conceito em contextos não ocidentais, porque remetido à sua conceção como propriedade privada, enquanto direito individual e exclusivo (Macpherson 1992 [1972]; Bhandar 2018).

Assim, analiso as delimitações das terras comunitárias e seus efeitos nos modos de conceber a propriedade a partir do enquadramento das principais disputas e conflitos (Macpherson 1992 [1972]; Peters 2009) e um olhar sobre 
a emergência de novas questões políticas, legais e éticas em torno da propriedade (cf. F. Benda-Beckmann, K. Benda-Beckmann e Wiber 2009 [2006]).

Metodologicamente, a pesquisa foi guiada pelo debate sobre as experiências de delimitação e demarcação de terras e o estatuto dos territórios dos chefes tradicionais. Estes chefes no seu conjunto são designados mafumu, o que inclui os chefes principais, designados régulos, e os chefes de territórios subordinados, conhecidos como nduna.

Parti do questionamento do estatuto atual dos territórios delimitados para compreender como estes estavam a ser incorporados no imaginário e na vivência quotidiana dos habitantes desta região. O material deste artigo foi baseado numa pesquisa etnográfica de cerca de dez meses, realizada entre 2012 e 2015. Durante o trabalho de campo contei com o apoio de um assistente, fluente em CiNyanja, língua falada no território em estudo.

À minha chegada em Cóbuè, fui falar diretamente com chefes tradicionais, seguindo sempre o princípio de hierarquia local, do mfumo para o nduna. Nos primeiros contactos comecei a notar o interesse do assistente em narrar-me as histórias da fundação do território Nyanja. Entre as pessoas que se diziam conhecedoras da história dos Nyanja constam os chefes tradicionais e as pessoas com alguma posição na hierarquia do poder tradicional. Visitei os ficheiros produzidos no ato da delimitação, onde encontrei esta mesma história territorial, que aparecia como "história da fundação da comunidade".

Muitos dos meus interlocutores partilharam várias explicações sobre o que significa ser dono das terras em Cóbuè a partir da história territorial. A partir dessas narrativas explorei aspetos relativos à identidade social, descrevendo os locais habitados e seus habitantes, a pertença e uso da terra, o poder dos chefes das unidades sociais de natureza linhageira e sua ligação com os direitos à terra e de propriedade das terras. Interessaram-me igualmente as disputas pelas terras e a forma como são interpretadas as mudanças introduzidas com a delimitação, a demarcação e a constituição das áreas de conservação de recursos naturais.

Neste artigo começo por apresentar o contexto etnográfico, para de seguida enquadrar os chefes tradicionais focando-me nos dois principais régulos da região. $\mathrm{O}$ artigo prossegue com a apresentação de uma experiência de venda de terrenos que nos guiará ao enquadramento das unidades sociais linhageiras e termina com uma reflexão sobre a posse e propriedade da terra.

$\mathrm{O}$ artigo contribui para o debate sobre as transformações dos regimes de propriedade como consequência das experiências de territorialização colonial e pós-colonial. Esta abordagem dialoga com a revisão feita por Peters (2009) sobre os debates antropológicos nas questões fundiárias em África, que mostra a intensificação de conflitos e novas modalidades de alienação de terras. Estas últimas marcadas por reivindicações de autoctonia e uma atenção especial na ligação entre terra e disputas pela autoridade dos chefes tradicionais. 


\section{CONTEXTO ETNOGRÁFICO}

Cóbuè é um posto administrativo do distrito do Lago, na província do Niassa, e serve de fronteira entre Moçambique e o Malawi, através do lago Niassa, e entre Moçambique e a Tanzânia, pelo rio Chiwindi. Esta província está situada no extremo noroeste de Moçambique, a cerca de $2800 \mathrm{~km}$ de Maputo, a capital do país, e é a maior província ( $16 \%$ do território nacional) e a menos povoada, aproximadamente 7,1 habitantes por quilómetro quadrado (Governo do Distrito do Lago 2012). ${ }^{5}$ Os seus habitantes falam maioritariamente CiNyanja, uma língua usada por cerca de $8,1 \%$ da população da província (INE 2019).

O relevo da região é marcado pela imponência do lago Niassa e pelas elevações montanhosas circundantes, de um lado vendo-se o Malawi e do outro a parte moçambicana. As áreas habitadas são influenciadas pelo perfil acidentado do relevo e onde a norma é a dispersão de habitações, marcadas por pequenos núcleos residenciais separados de entre $500 \mathrm{~m}$ a $1 \mathrm{~km}$ e por vezes mais. As habitações ocupam os lugares relativamente planos, se bem que escassos, ao longo das margens do lago Niassa, e seguem o curso dos rios, dos riachos e das águas pluviais, que descem dos pontos mais altos e montanhosos em direção ao lago.

Nesta região, as formas de mobilidade forçada foram determinantes para os padrões de povoamento, sobretudo entre finais do século XIX e início do século XX. Este período coincide com o estabelecimento da administração colonial portuguesa (cerca de 1905). A partir da segunda metade do século XIX, esta região foi palco de vários eventos que afetaram os seus habitantes, nomeadamente: (i) a presença dos missionários da University Mission for Central Africa (UMCA); (ii) o estabelecimento da administração colonial portuguesa e as disputas dos territórios coloniais entre Inglaterra, Portugal e Alemanha; (iii) a guerra pela independência de Moçambique (1975), que opôs a Frente de Libertação de Moçambique (Frelimo) e o Estado português (1964-1974); e, por último, (iv) a guerra civil (1976-1992), que envolveu o Estado de Moçambique e a Resistência Nacional Moçambicana (Renamo).

Quando se iniciou a guerra civil em 1976, muitas pessoas destas regiões ainda se preparavam, no âmbito da independência, para regressar às suas anteriores residências. Entretanto algumas terão permanecido nos locais de refúgio, em particular no Malawi, na Tanzânia e no interior de Moçambique. ${ }^{6}$ Alguns dos meus interlocutores, com idades entre os 25 e os 50 anos, chegaram pela primeira vez na região de Cóbuè depois de 1994, ano das primeiras eleições

5 A mesma taxa registada no censo de 2017 (disponível em http://www.ine.gov.mz/iv-rgph-2017/ mocambique/apresentacao-resultados-do-censo-2017-1, última consulta em dezembro de 2021).

6 Entre 1986 e1992, período da guerra civil, apenas as povoações de Mbandece, Maniamba, Metangula, Chiuanga, Messumba, Mechumua, Cóbue e Ngongo ficaram habitadas e as restantes povoações ficaram total ou parcialmente abandonadas (António 1996: 48). 
gerais e multipartidárias em Moçambique e dois anos depois do fim da guerra civil.

Mais recentemente, Cóbuè foi palco de duas experiências marcantes, com efeitos sobre a mobilidade forçada da população local. A primeira experiência foi em 2006, com a definição de uma área de conservação de recursos naturais (florestais e faunísticos) e envolveu a delimitação de terras comunitárias, ${ }^{7}$ que terminou no ano de 2007. ${ }^{8}$ A segunda foi em 2011 e compreendeu a definição de uma reserva parcial no lago Niassa. ${ }^{9}$

Como indicado acima, a delimitação das terras comunitárias foi feita em simultâneo com a demarcação de cerca de 120 mil hectares de área de conservação e a criação da respetiva associação comunitária. ${ }^{10}$ Fez-se igualmente a descrição dos interesses económicos, sociais e culturais nos limites territoriais, a demarcação das respetivas áreas, a produção de vários mapas dos territórios correspondentes às 16 comunidades identificadas. Deste modo, o processo de delimitação fixou as comunidades como territórios dos chefes tradicionais com primazia para os régulos e, ${ }^{11}$ por extensão, os nduna. ${ }^{12}$ Estes emergiram assim como os representantes das comunidades e, consequentemente, chefes e donos das terras.

O termo "comunidade" usado neste processo enfatiza o princípio de agregação a partir do entendimento de que a terra rural é pertença da comunidade

7 Do ponto de vista formal este processo é designado "delimitação das terras comunitárias" (Diploma Ministerial n. ${ }^{\circ}$ 29-A/2001, de 17 de março).

8 Ao abrigo da Lei de Terras a "comunidade local" é definida como sendo "agregado de famílias e indivíduos vivendo numa circunscrição territorial de nível de localidade ou inferior, que visa a salvaguarda de interesses comuns através de proteção de áreas habitacionais, áreas agrícolas, sejam cultivadas ou em pousio, florestas, sítios de importância cultural, pastagens, fontes de água e áreas de expansão" (art. 1, alínea 1, Lei n. ${ }^{\circ}$ 19/97).

9 Niassa tem sido palco de implementação de modelos de desenvolvimento baseados em monoculturas em grandes extensões territoriais (Åkesson e Nilsson 2006). Em 1997, a Sociedade de Desenvolvimento Mosagrius adquiriu 220 mil hectares de terra distribuídos nos distritos de Sanga (100 mil ha), Majune (100 mil ha) e Lago (20 mil ha). Entre 2005 e 2010 as companhias Chikweti Forests of Niassa, Fundação Malonda, New Forest Malonda, Companhia Florestal de Massangulo e Sociedade Florestas do Niassa tinham na sua posse cerca de 200 mil hectares, distribuídos pelos distritos de Lago, Lichinga, Sanga, Mandimba e Ngauma (Braga 2001, Minag 2010).

10 A delimitação ocorre numa altura que em Moçambique estava a ser reforçada a componente de terras comunitárias como mecanismo de promoção de desenvolvimento rural. A partir da abordagem popularizada pela "Iniciativa de Terras Comunitárias", um organismo criado no ano de 2006, a delimitação de terras é equiparada à criação de organizações de base comunitária (German et al. 2016).

11 O "Anexo Técnico da Lei de Terras"( Diploma Ministerial n. ${ }^{\circ}$ 29-A/2001, de 17 de março), que preconiza a produção da cronologia da comunidade, desde a sua fundação e os vários acontecimentos ao longo do seu percurso histórico, como parte da história da comunidade.

12 Foram assim definidas como comunidades, por exemplo, Ngofi (régulo), Chigoma (régulo Chiteji), Mataka (régulo Mataka), Chicaya (régulo Nyaya), Utonga (nduna do régulo Mataka), Khango (nduna do régulo Mataka), Mbweca (nduna do régulo de Uchessi), Uchessi (régulo), Magachi (régulo), Matepwe (régulo) e Mala (nduna do régulo Mataka). 
e onde os direitos individuais são pensados no quadro das normas e práticas costumeiras. Esta abordagem não é totalmente nova e está presente nas experiências do encontro entre os habitantes desta região do lago Niassa com os missionários e a administração colonial. A mesma foi seguida por quase toda a África quando os regimes coloniais transformaram os direitos e obrigações centrados nas relações entre pessoas em direitos sobre a terra (Potier 2005). Historicamente, o legado de fazer coincidir a terra com entidades (comunidades) políticas tem resultado na criação de um novo tipo de autoridade local com poderes sobre a terra.

Contrariamente ao modelo que estabelece a delimitação de terras como momento de confirmação dos limites das comunidades, para os habitantes de Cóbuè esta experiência serviu para atualizar a história territorial e, com isso, a definição de quem é de facto o dono da terra. Foi a partir do processo de delimitação que o debate sobre as hierarquias entre os chefes tradicionais e respetivos territórios se tornou num assunto público intermediado pelo chefe do posto administrativo.

\section{CHEFES TRADICIONAIS E OS TERRITÓRIOS DELIMITADOS}

Banidos em 1975, aquando da proclamação da independência de Moçambique, na década de 1990 os chefes tradicionais e toda a estrutura do poder tradicional que vigorou na altura da administração colonial portuguesa voltaram a ser vistos como representantes das comunidades rurais (Forquilha 2006; Florêncio 2008). A aprovação do Decreto n. ${ }^{0}$ 15/2000, de 20 de junho, ${ }^{13}$ foi determinante para a incorporação dos chefes tradicionais na administração do Estado, ao serem definidos como autoridades comunitárias (Gonçalves 2006; Meneses 2009).

Em Cóbuè, as hierarquias entre os chefes tradicionais seguem o modelo criado ainda no período colonial, entre o Régulo e seus nduna. Os chefes tradicionais foram constituídos como chefes de terras, primeiro pelos missionários, através da construção de uma história baseada em chefaturas e que circunscreveu as lideranças tradicionais a um determinado território. Seguiu-se a administração colonial portuguesa que estabeleceu uma estrutura administrativa e militar por via da coaptação das lideranças tradicionais. ${ }^{14}$

13 O Diploma Ministerial 107-A/2000, regula o Decreto n. ${ }^{\circ}$ 15/2000, de 20 de junho, sobre as formas de articulação dos órgãos locais do Estado e as autoridades comunitárias.

14 O "Estatuto político, civil e criminal dos indígenas da Guiné, Angola e Moçambique" e a "Lei da Reforma Administrativa Ultramarina" (RAU) foram instrumentos determinantes na integração dos chefes tradicionais na organização territorial (Forquilha 2006, Florêncio 2005, 2008). Para Medeiros (2006) a colonização portuguesa transformou os chefes pequenos em régulos e os sues territórios em regulados. 
Neste novo contexto, o Estado multiplica as esferas e mecanismos de participação e lógicas de representação, o que tem vindo a produzir uma diluição do âmbito de atuação das lideranças tradicionais. Esta situação abre espaço a uma negociação quase quotidiana da relação entre, por um lado, os representantes do Estado e as lideranças tradicionais e, por outro lado, no seio das próprias lideranças tradicionais e entre outros focos de poder incorporados na designação autoridade comunitária. ${ }^{15}$ Esta negociação estende-se à relação entre as lideranças tradicionais e a população que habita o território sob sua jurisdição.

Apesar de cada chefe tradicional se definir pelo seu território, fica claro que entre eles se disputa a sua hierarquização, como evidenciado no caso que discuto neste artigo, entre os régulos Mataka e Chiteji e entre o Mataka e os seus nduna. Estas disputas resultam, em parte, do "modelo da tradição", que não corresponde às práticas costumeiras da terra em Moçambique, que transformou os chefes tradicionais em donos das terras e respetivos territórios (Gengenbach 2005). ${ }^{16}$

Como referido na secção anterior, as terras foram delimitadas em Cóbuè usando como referência os chefes tradicionais a partir das narrativas feitas por eles em relação ao tempo histórico. Este processo de delimitação de terras teve o pendor de atualizar a hierarquia entre os chefes tradicionais. Por um lado, o régulo Mataka, que ficou com os territórios da área de conservação comunitária, os terrenos da sede do posto administrativo e os territórios ocupados pelo empreendimento turístico, totalizando cerca de 200 mil hectares, por outro lado, o régulo Chiteji que surge nas narrativas territoriais como o fundador dos Nyanja da região do lago Niassa.

O régulo Chiteji, do território (comunidade) de Chigoma, ocupa o topo da hierarquia dos chefes tradicionais recorrendo à história da fixação dos Nyanja ao longo do lago Niassa. Chiteji é descrito pelos missionários britânicos da University Mission for Central Africa (UMCA), em finais do século XIX, como o chefe que cedeu as terras para a construção de missões em toda a região, principalmente a sede desta missão construída na ilha de Likoma. A sua preponderância na região de Cóbuè é confirmada pela construção da maior igreja anglicana nesta região, a escassos metros da atual residência do régulo. ${ }^{17} \mathrm{Na}$ versão do missionário William Johnson, o Chiteji faz parte do grupo

15 As reformas administrativas do Estado moçambicano iniciadas na década de 1990, que introduziram as autoridades comunitárias, estipularam igualmente a hierarquia entre os chefes tradicionais e as autoridades administrativas denominadas secretários (secretário de bairro ou secretário da povoação). 16 Isso correspondeu à criação das figuras do "régulo", "cipaios", "cabos de terra", "chefes de grupo" e de "povoação" (Åkesson e Nilsson 2006: 43).

17 Existe uma igreja anglicana em cada domicílio de um chefe tradicional. 
proveniente de oeste e que seguiu o sentido sul-norte, ao longo do lago Niassa, tendo habitado em vários lugares nomeados pelos missionários, ${ }^{18}$ antes de se fixar definitivamente em Chigoma (Johnson 1922).

O atual régulo Chiteji é o segundo na sucessão depois daquele mencionado pelos missionários. O facto de ter recebido os missionários britânicos e os primeiros portugueses, no início do século XX, é incorporado na história territorial do Chiteji para fundamentar a sua posição de régulo mais importante da região do lago Niassa, ${ }^{19}$ sobretudo de Cóbuè. ${ }^{20}$

Voltando à história territorial de Mataka de Cóbuè, produzida no ato da delimitação, que reconstrói a sua trajetória migratória num percurso que se inicia no interior de Moçambique no sentido este-oeste, numa região conhecida por Mwembe, terra originária dos Yawo (Alpers 1969; Liesegang 1984). Nesta trajetória, destacam-se momentos de rutura e integração, com recurso a referentes como a guerra com os Ngoni e a chegada dos portugueses em 1920. A descrição prossegue com a chegada da Frelimo em 1962, o ataque ao Posto Administrativo de Cóbuè pelos guerrilheiros da Frelimo em 1965, indiciando a entrada da guerra colonial nesta região. Neste ponto é referida a prisão e o assassinato do régulo Mataka pelos portugueses, ao que se indica acusado de prestar apoio à Frelimo. Por fim, os últimos acontecimentos marcantes em 1975, ano da independência de Moçambique, e 1991, ano do fim da guerra civil e do retorno da população que se havia refugiado.

A vastidão dos territórios de Mataka, que contemplam os territórios dos nduna Zumani, Bwanali, Minofo, Khuni e Matukwanu, é um dos aspetos que despoletou as reconfigurações recentes sobre a história e hierarquia entre os chefes. Por um lado, porque as demandas das reformas político-administrativas ${ }^{21}$ requerem a definição do representante dos chefes tradicionais no diálogo com o Estado e as organizações não governamentais (ONG). Por outro lado, as disputas entre o secretário da povoação-sede de Khango e o nduna Minofo pelo controlo e distribuição das terras na sede do posto administrativo de Cóbuè

18 Os lugares nomeados localizam-se ao longo do lago Niassa, tais como Chilowelo, próximo de Makanjila, depois em Messumba, próximo de Metangula, sendo o principal centro da igreja anglicana nesta região.

19 Um protagonismo que partilha com o régulo Massumba, da região de Messumba, e o régulo Chilombe, de Metangula.

20 As versões mais consensuais sobre a história territorial da região do lago Niassa reproduzem esta versão, caso por exemplo da obra de Asahel Mazula (1962) (citado por Huhn 2013: 37-42), que descreve o povoamento da região do lago Niassa, desde Metangula até à atual fronteira norte de Moçambique. Para este autor, a chegada do chefe Karonga Chimbano, que tomou o nome de Masumba (Chimbano), Kapazi e seus irmãos Chilombe e Mapunda marca o início do povoamento dos Nyanja na região. Mazula descreve também a chegada do Chiteji ao lago Niassa, que inclui uma passagem pela ilha de Likoma e a sua fixação em Chigoma (Ambali citado por Huhn 2013: 43-44).

21 O Diploma Ministerial 107-A/2000, regula o Decreto n. ${ }^{\circ}$ 15/2000, de 20 de junho, sobre as formas de articulação dos órgãos locais do Estado e as autoridades comunitárias. 
mostram a sobreposição de tipos de autoridade sobre o território, o que favorece disputas pelo controlo das terras.

O nduna Minofo foi consagrado como chefe da comunidade no processo de delimitação, na qualidade de autoridade tradicional de Cóbuè-sede, entretanto subordinado ao régulo Mataka, e controla de forma direta as terras próximas da sua residência. Por sua vez, o secretário de Khango, beneficiando do seu estatuto de autoridade administrativa territorial subordinada ao chefe do posto administrativo de Cóbuè, controla as mesmas terras reivindicadas pelo nduna Minofo. Entretanto, tanto as disputas como as transações que aconteciam não eram informadas e muito menos mereciam a aprovação do régulo respetivo.

A figura de secretário surgiu após a independência de Moçambique, quando se pretendeu desligar os chefes tradicionais do exercício de poder administrativo. Mas a substituição não decorreu de forma linear e a recuperação dos chefes tradicionais revelou outra faceta deste dinamismo. No caso particular de Cóbuè, o secretário da povoação está vinculado ao mesmo grupo de descendência linhageira do nduna Minofo, e teria estado na disputa pela sucessão do nduna, após seu falecimento em 2015. Por isso, a disputa entre os dois não se limitava apenas a estas sobreposições do poder formal atribuído pelo Estado, mas da posição hierárquica das suas unidades sociais, definidas em termos de descendência matrilinear. ${ }^{22}$ Esta questão de hierarquia entre as unidades sociais e sua ligação com a hierarquia dos territórios é analisada nas secções que se seguem.

Neste caso em particular, o território como lugar de disputas de hierarquias entre chefes tradicionais junta temporalidades e historicidades de longa duração na negociação da identidade e de estatutos, para manifestar a territorialidade. Falar da identidade é mergulhar no universo das relações e da linguagem usadas para definir quem são os donos da terra em Cóbuè.

\section{"POR QUANTO TEMPO VAIS FICAR COM A TERRA?"}

A partir de uma experiência de venda de terrenos demarcados como parte da “comunidade de Mataka", no território do nduna Khuni, analiso nesta secção as várias possibilidades de reivindicação da propriedade da terra para enquadrar o que significa um chefe tradicional ser considerado o dono das terras.

Um dos aspetos que destaquei durante as negociações nestas transações de terrenos deu-se no ano 2013, quando os donos da terra perguntaram à pessoa interessada em ocupar aquela porção se era por empréstimo (tempo limitado) ou se seria uma transferência de propriedade (tempo ilimitado), no exemplo do título da secção. Após a identificação dos limites do primeiro terreno, foram 
necessárias três rondas de negociações até ao desfecho da transação. Na primeira ronda, a pessoa interessada em ocupar o terreno começou por pedir para ser aceite como "filho do nduna". ${ }^{23}$ Neste primeiro encontro o nduna, depois de ouvir o pedido, solicitou que regressassem num outro dia porque pretendia consultar outros membros da família. O regresso do interessado, numa outra ocasião, aconteceu na presença do nduna, do filho da filha da irmã mais velha da mãe do nduna (o mais velho entre os três), o filho da sua filha e o seu filho. Os presentes, que representam aqui os donos da terra, pediram mais tempo para pensar nas condições a exigir pelo terreno. Neste mesmo dia foi feita uma visita ao terreno para a identificação dos limites. A terceira ronda foi para anunciar as condições de cedência do terreno e foi liderada pelo filho da filha do nduna, acompanhado pelo filho do nduna.

Ao olhar para as pessoas presentes nestas negociações, destaca-se o vínculo de parentesco, por referência a uma descendência traçada a partir das mulheres, nomeadamente, a irmã mais velha da mãe do nduna, a irmã mais velha do nduna e a filha do nduna. Todos eles mostraram ter legitimidade para decidir sobre os terrenos e que dominavam os respetivos limites. Os terrenos em questão estão localizados próximo do lago e caem no domínio das terras em pousio, que não apresentam sinais evidentes de ocupação para residência ou cultivo, o que faz delas matéria de debate em volta do seu controlo.

Em 2014 apareceu um segundo interessado, a quem chamaram "branco", que pretendia ocupar um terreno na mesma área. A negociação desta transação foi liderada pelo filho da irmã da mãe do nduna, juntamente com os outros intervenientes que estiveram na primeira negociação. Entretanto, nesta segunda transação os limites que haviam sido indicados para o primeiro requerente foram transpostos. Mulemba, filho da irmã mais velha do nduna, e chefe do muji Mulombwa, assumiu a sua posição de mais velho na hierarquia das unidades sociais linhageiras (muji), por ser a primeira descendência (bele la likulu). Iniciou um debate sobre o princípio da hierarquia destas unidades sociais, que pôs em causa a primeira transação do terreno liderada pelo filho da filha da irmã mais velha da mãe do nduna Khuni. Esta foi a explicação encontrada para a sobreposição dos limites dos terrenos entre aquele cedido pelo nduna Khuni, na primeira transação, e o cedido pelo Mulemba, na segunda transação.

Na segunda transação, o Mulemba foi quem mostrou os novos limites dos terrenos, identificados como os limites entre os dois territórios. O desfecho do caso, em 2015, implicou o ajustamento dos limites dos terrenos que estavam em disputa e, consequentemente, dos limites dos territórios entre as duas unidades linhageiras. Da disputa, o nduna Khuni não se livrou da acusação, embora sem consequências formais, da violação do princípio da hierarquia 
linhageira na primeira transação. Ora, os terrenos que estavam a ser disputados eram parte do território reivindicado pelo muji Umbalo. Umbalo e Mulombwa são unidades que compõem a estrutura do poder tradicional de Utonga, ${ }^{24}$ liderada pelo nduna.

Ficou visível que o nduna não exerce direito efetivo sobre os terrenos consignados no seu território, já para não falar da figura do régulo, que não foi ouvido nestas transações. Estes exemplos obrigam-nos a regressar ao ponto explicitamente apresentado por Gluckman (1944), ${ }^{25}$ que evidencia que cada unidade social tem direitos sobre a terra e que estes direitos constituem parte das relações entre as unidades sociais respetivas.

Os meus dados ajudam a reforçar a ideia de que para cada tipo de uso estão implicados direitos específicos sobre uma determinada terra. Assim, as hierarquias entre os diferentes níveis de estruturação de unidades sociais não condicionam, de todo, o acesso à terra, mas determinam a definição do estatuto daqueles que detêm o poder de controlar as terras, decidir sobre sua transferência ou alocação a terceiros, sobretudo os de fora das unidades sociais respetivas.

Esta constatação levou-me a olhar a posse da terra como uma relação entrelaçada entre a terra pertencer às pessoas e as pessoas pertencerem à terra (Strathern 2009) e a pensar como as pessoas definem a categoria de "dono da terra" em Cóbuè.

A dimensão comunitária revela aqui a sua complexidade, no sentido em que dentro do grande território da comunidade (formal), os referentes identitários que fundamentam a posse se fragmentam em segmentos que correspondem às modalidades da inter-relação social, revelando a diferenciação e competição pelo controlo do território. Na secção que se segue procuro explicitar a forma de organização social e doméstica assente no muji, como pressuposto da fragmentação.

\section{POSSE E PROPRIEDADE DA TERRA EM TORNO DO MUJI}

Falar da posse e propriedade da terra passa pela contextualização de um princípio dominante entre os habitantes de Cóbuè, que estabelece que mais de duas gerações terão ocupado de forma continuada a mesma parcela. Este princípio é definido a partir do muji, que se equipara ao conceito de "casa" enquanto "unidade de identificação e de vivência social" (Viegas 2007: 100).

Os meus interlocutores com algum conhecimento da língua portuguesa traduziram muji como "família" e o meu assistente de campo interpretou muji

24 Designação do território, "Comunidade de Utonga", e liderado pelo nduna Khuni, parte da comunidade delimitada de Mataka.

25 Cita os trabalhos de M. Wilson, M. Fortes, A. Richards, C. Dundas, E. Evans-Pritchard e S. Nadel, e uma análise exaustiva dos trabalhos de I. Schapera e M. Green, ambos realizados na década de 1940. 
como uma "comunidade" e lugar onde as pessoas vivem e produzem. ${ }^{26}$ Estas conceções mostram a incorporação da linguagem dominante das intervenções rurais, onde o termo comunidade define os agrupamentos ou agregação de escala territorial indefinida. O conceito de família como o de comunidade, no sentido usado pelos meus interlocutores, associa muji a modelos de socialidade e de inscrição territorial que sublinham as várias dimensões de manifestação da territorialidade.

Como primeiro enquadramento da questão, a identidade primária é estabelecida em torno da descendência unilinear matrilateral. O tio materno, $n k h o s w e,{ }^{27}$ descreve todos os homens em relação às mulheres e é o primado da constituição das unidades sociais (muji). O chefe da unidade é encontrado entre os tios maternos representantes de cada ramificação. ${ }^{28}$ Acima do chefe de cada muji encontra-se o superior hierárquico de todos os chefes das unidades sociais que se reconhecem como parte da mesma unidade política e territorial, designado a mkulu wa miji, que é a posição ocupada pelas chefias tradicionais (mafumu $=$ todos os chefes ou $m f u m u=$ chefe). Como princípio de hierarquia, as unidades sociais definem a sua posição relativa na configuração das unidades políticas representadas por cada um dos chefes tradicionais (nduna ou régulo) e, consequentemente, a hierarquia dos respetivos territórios.

Por exemplo, o muji articula outros dois níveis de pertença: o fuko e o khamu. O termo fuko inclui membros da parentela da parte materna (akucikazi) e da parte paterna (akucimuna), identificados a partir de suas genealogias (cilawa). O khamu corresponde à identificação da unidade doméstica ou domicílio. O fuko inclui os parentes consanguíneos acentuando principalmente um nível de descendência cognática, ${ }^{29}$ e é o garante da integração do apelido (ciwongo) do pai na identificação de uma pessoa, que consta do nome de registo e é usado por homens adultos como nome próprio. ${ }^{30}$ Em regra, os homens adultos não são tratados pelo primeiro nome e o apelido materno é omisso. Da parte

26 Maganizo, assistente da pesquisa (Cóbuè, março de 2015).

27 Seu equivalente na literatura antropológica clássica foi descrito como o princípio de segmentação linhageira (cf. Bruwer 1955; Mitchell 1956; Van Velsen 1971 [1964]; Turner 1957).

28 Chefe - Bwana na língua Swahili, com origem na palavra árabe $a b \bar{u} n \bar{a}$ que significa "nosso pai". Bwana é um termo usado para referir as pessoas importantes, por vezes no sentido de chefe e quando se trata do muji refere-se ao chefe do muji, mkulu pa muji.

29 Van Velsen (1971 [1964]: 73) afirmou que os Tonga possuíam dois conjuntos de parentes: patrilaterais e matrilaterais. Mostrou que as pessoas recorriam sistematicamente aos dois vínculos, para o que contava muito a proximidade geográfica.

30 Van Velsen (1971 [1964]) explicou esta tendência de transmissão do nome pela via paterna no contexto matrilinear, como resultado da introdução do modelo patrilocal e patrilinear, pelos Nguni e missionários. Como exemplo cita o nome do batismo que obrigou as pessoas a incluir o nome do pai no seu próprio nome. Antes M. Marwick (1952) e J. P. Bruwer (1955) referiram-se ao ciwongo como nome do clã. 
materna as pessoas evocam o nome do muji que é ostentado pelo respetivo tio materno (nkoswe), que pode ser igualmente o chefe do muji. As mulheres, tal como os homens, não são tratadas pelo primeiro nome mas, diferentemente dos homens, não usam o ciwongo do pai como nome próprio. Elas são tratadas por referência ao seu nkoswe ou muji seguindo o seguinte formato: mbumba wa bwana $X$, onde $X$ corresponde ao nome do nkhoswe ou do muji.

O termo muji congrega, assim, os modelos de organização social ao mesmo tempo que é usado para descrever formas de territorialidade. Os princípios que conferem o estatuto de pessoa são a base para definir a posição de chefe do muji entre aqueles que se definem por parentela ou aliança a um antepassado comum, descrito como o fundador do muji e do território. O chefe do muji é definido a partir de uma referência que o liga ao fundador e é negociado entre aqueles que se apresentam como a descendência das ramificações ou descendência identificadas num determinado muji.

Estes arranjos seguem um esquema que hierarquiza as descendências na ordem de sucessão, para definir a ramificação matrilateral dominante. Este estatuto ou posição dominante pode alternar-se entre as diversas ramificações (mawele) dentro do mesmo muji, quando se trata de determinar quem é o chefe do muji. A alternância também decorre no momento de sucessão dos mafumu (régulo e nduna) e aqui a negociação decorre entre as ramificações dentro de cada muji e depois entre os diferentes miji, resultando assim numa escalada de negociações, dependendo da extensão destas unidades sociais nos respetivos territórios. Em torno dos muji confluem os princípios de descendência, de sucessão e de definição territorial, daí a sua centralidade na identificação de unidades políticas territoriais, aquelas associadas aos nduna e os mafumu (régulos). Mais ainda, o muji favorece a centralidade da narração da história territorial na definição das hierarquias sociais, tanto das unidades sociais como dos respetivos territórios.

Além das hierarquias entre os chefes tradicionais e dos territórios, o muji é definidor das categorias de identidade social. Para uma pessoa adulta, homem ou mulher, o primeiro critério de referência territorial é o seu domicílio ou casa. $^{31} \mathrm{O}$ espaço ocupado por uma casa é localizado por referência ao território do muji onde o seu respetivo chefe é considerado o "dono da terra". Em CiNyanja chama-se khamu e muji aos lugares domésticos, a menor destas unidades habitada por um grupo doméstico, e diz-se malo, dela ou ciwago para referir as terras. Malo é igualmente usado para os territórios associados ao muji e outros escalóes das chefias tradicionais. Diga-se que a distinção entre um grupo doméstico e muji não é morfológica e não se reduz apenas à sua 
localização. ${ }^{32}$ Ela apenas sublinha a intensidade das interações sociais entre os seus membros e uma história da fundação dos territórios.

Reside aqui a importância da residência como dimensão importante na constituição de um sentido mais preciso de pertença e propriedade da terra. As pessoas que pertencem à mesma unidade de residência passam a reconhecer-se como parte de uma mesma unidade social (cf. Rival 2002). O muji assume assim o sentido de unidade social primária (cf. Pina-Cabral 1991).

\section{A HISTORICIDADE DO TERRITÓRIO COMO OBRA DOS ANTEPASSADOS}

Veremos, a partir do exemplo dos chefes tradicionais, a forma como descrevem a historicidade do território e seus habitantes como obra do(s) primeiro(s) ocupante(s). Com base nessa descrição, será possível contextualizar a posição dos chefes tradicionais como donos das terras em Cóbuè.

Um dos aspetos que chama a nossa atenção é o facto de os chefes tradicionais se constituírem a partir de uma base territorial. Por isso, para estes habitantes de Cóbuè existe uma distinção entre "chefes com terras" e os "chefes pelas pessoas", em que prevalece a centralidade dos vínculos interpessoais no seio do muji. No primeiro caso, os chefes descendem da linha materna, bele ou do muji, dos fundadores, uma posição que favorece a reivindicação do estatuto de dono das terras. No segundo caso, encontram-se os chefes que ascenderam à posição mas em que a sua bele ou muji não corresponde àquela que controla os territórios.

Esta última situação foi criada, em parte, pelo intervencionismo colonial e no período subsequente na indicação de chefes tradicionais, que resultou na extensão da noção do primeiro ocupante a uma escala territorial maior e forçou a incorporação de muitos outros primeiros ocupantes numa única narrativa de legitimação das chefias tradicionais.

O chefe que se encontra na última condição é obrigado a negociar, de forma permanente, a sua legitimidade e a governação dos territórios com os membros de outras unidades sociais, que reivindicam e são reconhecidos como descendentes de um dos antepassados fundadores.

Cito aqui o régulo Chiteji quando explica a sua posição na hierarquia do poder tradicional nos seguintes termos:

"Todos os habitantes são do mesmo muji. O mfumu tem poder sobre a terra e as pessoas porque quem chegou primeiro é o dono das terras. Assim, a ordem de chegada determina quem manda sobre as terras e as pessoas que

32 Um povoamento é constituído por pessoas que se identificam com mais de um muji. Muji, enquanto unidade social e de residência, não se restringe à uma localização física de um aglomerado de pessoas e casas, a "aldeia matrilocal", linhagens (Van Velsen 1971 [1964]; Turner 1957; Mitchell 1956) ou "comunidade". 
chegaram depois devem obediência ao mfumu. Os miji que chegaram primeiro também são donos das terras onde vivem e o mfumu não tem poder sobre essas terras." [Conversa com mfumu Chiteji; Cóbuèbuè, maio de 2013].

O chefe Chiteji explicou assim o estatuto destes miji que considerou serem donos das terras, revelando que aquelas pessoas que chegaram com o primeiro mfuти Chiteji foram transformadas em chefes de terras (nduna). O Chiteji descreveu-me a sua relação com um dos nduna de nome Chekani para exemplificar esta condição:

"O Chekani chegou depois do primeiro Chiteji. O Makunyula também chegou depois do Chiteji. À sua chegada o Chekani escolheu um lugar para se fixar e depois foi pedir autorização ao Chiteji. Mais tarde o Chiteji nomeou Chekani como nduna dessa área. Chekani significa 'fechar o limite' porque o território do nduna Chekani faz limite com o régulo Mapunda.” [Conversa com mfumu Chiteji; Cóbuè, maio de 2013].

A história do Chiteji evidencia a complexidade das dinâmicas territoriais, o que torna estas narrativas num lugar de encontro de processos de longa duração, tal como foi sublinhado por Lentz (2013). São várias as versões destas narrativas e são ditas pelos nduna, pelos chefes do muji e outras pessoas importantes, e o seu denominador comum é a ênfase na primazia da chegada ao território. Os episódios narrados fixam determinados pontos na paisagem, esclarecem a génese dos nomes dos lugares e integram várias temporalidades e historicidades.

Pelas narrativas, a condição de dono das terras é repartida entre a descendência dos consagrados como fundadores do território. Pela narração dos episódios da fundação dos territórios, a posição de chefe emerge como herança dos antepassados. O território reforça a sua dimensão política, como se o espaço fosse, ele próprio, a matéria fundadora da hierarquia política (Strathern 2009).

\section{CONCLUSÃO}

Os dados de Cóbuè revelaram que os chefes (régulos e nduna) não são os únicos donos da terra. Os esforços desencadeados por missionários, administração colonial portuguesa, Estado pós-colonial e pelo processo de delimitação de terras comunitárias, de transformar estes chefes em donos da terra, resultaram na diluição dos critérios da sua legitimação no seio de grupos sociais de referência.

Quando terminou a delimitação de terras comunitárias em Cóbuè, em 2007, ficou confirmada a chegada de mais uma modalidade de intervenção sobre os territórios, desta vez em nome do desenvolvimento. A Lei de Terras de 1997 respondeu ao imperativo neoliberal do uso produtivo das terras, introduzindo 
a componente terras comunitárias como regidas por normas e práticas costumeiras. Acreditava-se que as comunidades, com a assistência das ONG, iriam juntar-se para tirar o proveito da procura de terra por investidores privados.

O que acabei de descrever não invalida nem diminui a tendência de os chefes tradicionais, no seu dia a dia, agirem e incorporarem o papel de donos do território, uma realidade viabilizada pela prática governativa, do Estado e das ONG, que os coloca na posição de interlocutores privilegiados em todas as suas intervenções, incluindo a gestão e distribuição de recursos.

No entanto, viu-se como a legitimidade dos chefes e o acesso e distribuição de terras são garantidos pelo muji e respetivos segmentos. Assim, o controlo, distribuição e uso da terra, considerados como direitos dos chefes, foram debatidos por pessoas com estatutos e idades diferentes. A ideia de que seriam os chefes ou os mais velhos a assumir este papel de controlar e distribuir a terra mostra aqui uma outra faceta, onde a senioridade é situada ao nível da posição relativa ocupada pela unidade social na respetiva hierarquia. A ligação ao antepassado fundador do território, assegurada pela história territorial, abre espaço para a inclusão de núcleos dispersos e pessoas cujos estatutos advêm da pertença a um muji.

As narrativas histórico-territoriais, usadas para definir a comunidade, revelam a sua maleabilidade pela incorporação de temporalidades e historicidades que marcaram as experiências dos habitantes do lago Niassa, durante vários séculos, com o território. Como se viu, estas mesmas histórias territoriais têm várias versões, conhecidas e debatidas pelos seus membros. Caso para sublinhar a dimensão estruturante das narrativas da fundação dos territórios nas relações sociais, enquanto princípio de valor, constructo cultural e social, incluindo nas relações de propriedade, parte do debate sobre a natureza dos sistemas costumeiros da terra (cf. Lentz 2006, 2010, 2013).

O resultado da produção de uma história única sobre os chefes e seus territórios, feita durante os vários processos de territorialização, foi a interrupção da fluidez, maleabilidade e negociabilidade que caraterizaram e continuam a caraterizar os sistemas costumeiros de terra. Assim se justifica a multiplicação de focos de contestação, sobretudo no momento atual em que a terra se vai mercantilizando. A contestação ocorre, por exemplo, nos desacordos sobre o estatuto do primeiro ocupante, o que torna a identificação dos donos das terras num lugar de negociação permanente. Estes aspetos ajudam a repensar a natureza dos direitos comunitários, incluindo a forma como se projeta a comunidade como detentora de direitos sobre a terra, questionando o pressuposto da agregação e homogeneização que caraterizam as práticas de delimitação das terras comunitárias atualmente em vigor. ${ }^{33}$

33 No ano 2020 iniciou o processo de revisão da Política Nacional de Terras, da Lei de Terras e da legislação associada. 
A partir de autores como Lentz (2013, 2010, 2006) e Peters (2009) centralizei a análise das principais disputas de terras a partir da noção de território, uma vez que em Cóbuè estava em causa a definição do estatuto de quem controla e pode decidir sobre a terra. ${ }^{34}$ Portanto, a delimitação das terras comunitárias representou a transformação de práticas de uso da terra em noções de posse e direitos sobre o território, algo que tem vindo a concorrer para as mudanças no valor atribuído à terra. Aqui verifica-se, tal como em algumas partes de África (cf. Geschiere 2004, 2009; Geschiere e Nyamnjoh 2000; Chauveau e Richards 2008), a emergência de formas radicais na definição dos limites dos grupos sociais de pertença, que desafiam a ideia de comunidade constituída em torno do chefe.

34 Em Moçambique cresce a olhos vistos o mercado de terras, tanto em contextos urbanos como rurais, uma prática contrária à Lei de Terras (Negrão 2008; Oram 2010; Mandamule 2017). Estas práticas favorecem a intensificação deste tipo de disputas e conflitos. 


\section{BIBLIOGRAFIA}

ÅKESSON, Gunilla, André CALENGO, e Christopher TANNER, 2008, "Não é uma questão de fazer ou não fazer: é uma questão de como fazer. Estudo sobre terras comunitárias, província do Niassa, Moçambique”. Maputo: Relatório de estudo encomendado pela ASDI.

ÅKESSON, Gunilla e Anders NILSSON, 2006, Governação Nacional e Chefatura Local: Uma Avaliação Multi-Nível do Poder de Moçambique da Perspectiva do Niassa. Maputo: relatório de estudo encomendado pela ASDI.

ALPERS, Edward A., 1969, "Trade, state, and society among the Yao in the nineteenth century”, The Journal of African History, 10 (3): 405-420.

ANTÓNIO, Alexandre, 1996, Problemas e Processos de Reconstrução Social Pós-Guerra Civil: O Caso do Distrito do Lago Niassa. Maputo: Universidade Eduardo Mondlane, monografia de licenciatura em História.

BENDA-BECKMANN, Franz Von, Keebet Von BENDA-BECKMANN e Malanie G. WIBER, 2009 [2006], "The properties of property”, in Franz Von Benda-Beckmann, Keebet Von Benda-Beckmann e Malanie G. Wiber (orgs.), Changing Properties of Property. Londres: Berghahn Books, 1-44.

BHANDAR, Brenna, 2018, Colonial Lives of Property: Law, Land, and Racial Regimes of Ownership. Durham: Duke University Press.

BOHANNAN, Paul, 1973 [1963], “'Land', 'tenure' and land tenure”, in Daniel Biebuvck (org.), African Agrarian Systems. Oxford: Oxford University Press.

BOWEN, Merle, 2000, The State Against the Peasantry: Rural Struggles in Colonial and Postcolonial Mozambique. Charlotte: The University Press of Virginia.

BRAGA, Carla M.T., 2001, Matrilinearidade, Desenvolvimento e Terras no Âmbito do Programa MOSAGRIUS em Issa Malanga, Niassa. Maputo: Faculdade de Letras e Ciências Sociais, Universidade Eduardo Mondlane, trabalho de licenciatura.

BRUCE, John W., 1993, "Do indigenous tenure systems constrain agricultural development?", in Thomas Basset e Donald Crummey (orgs.), Land in African Agrarian Systems. Madison: University of Wisconsin Press, 35-56.

BRUWER, J.P., 1955, "Unskhoswe: the system of guardianship in Cewa matrinileal society", African Studies, 14 (3): 113-122.

CHAUVEAU, Jean-Pierre, e Paul RICHARDS, 2008, "West African insurgencies in agrarian perspective: Côte d'Ivoire and Sierra Leone compared", Journal of Agrarian Change, 8 (4): 515-552.

COUSINS, Ben, 2008, "Characterising 'communal' tenure: nested systems and flexible boundaries", in Aninka Claassens e Ben Cousins (orgs.), Land, Power and Custom: Controversies Generated by South Africa's Communal Land Rights Act. Cape Town: UCT Press; and Athens: Ohio University Press, 109-137.

DE WIT, Paul de, e Simon NORFOLK, 2010, "Reconhecer direitos sobre os recursos naturais em Moçambique”, Rights Resources Initiative. Maputo: s. ed.

FLORÊNCIO, Fernando, 2005, Ao Encontro dos Mambos: Autoridades Tradicionais VaNdau e o Estado em Moçambique. Lisboa: Imprensa de Ciências Sociais.

FLORÊNCIO, Fernando, 2008, "As autoridades tradicionais vaNdau de Moçambique: o regresso do indirect rule ou uma espécie de neo-indirect rule?", Análise Social, XLIII (187): 369-391. 
FORQUILHA, Salvador C., 2006, “Des 'autoridades gentílicas' aux 'autoridades comunitárias': le processus e mobilisation de la chefferie comme ressource politique: Etat, chefferie et démocratisation au Mozambique: les cas du district de Cheringoma". Bordéus: Centre d'Etude d'Afrique Noire, Université de Bordeaux IV, tese de doutoramento em ciência política.

GENGENBACH, Heidi, 2005, Binding Memories: Women as Makers and Tellers of History in Magude, Mozambique. Nova Iorque: Columbia University Press.

GERMAN, Laura, Eunice CAVANE, Almeida A. SITOE, e Carla BRAGA, 2016, "Private investment as an engine of rural development: a confrontation of theory and practice for the case of Mozambique", Land Use Policy, 51: 1-14.

GESCHIERE, 2004, "Ecology, belonging and xenophobia: the 1994 forest law in Cameroon and the issue of community", in Harri Englund e Francis B. Nyamnjoh (orgs.), Rights and the Politics of Recognition in Africa. Londres e Nova Iorque: Zed Books, 237-261.

GESCHIERE, Peter, 2009, Perils of Belonging: Autochthony, Citizenship, and Exclusion in Africa and Europe. Chicago: The University of Chicago Press.

GESCHIERE, Peter, e Francis NYAMNJOH, 2000, "Capitalism and autochthony: the seesaw of mobility and belonging", Public Culture, 7 (2): 423-452.

GLUCKMAN, Max, 1944, "Studies in African land tenure", African Studies, 3 (1): 14-21.

GONÇALVES, Euclides, 2006, "Local powers and decentralisation: recognition of community leaders in Mocumbi, Southern Mozambique", Journal of Contemporary African Studies, 24 (1): 29-52.

GOVerno DO Distrito DO LAGO, 2012, Plano Distrital de Uso da Terra: Diagnóstico da Situação Actual. Metangula: Governo do Distrito.

HANLON, Joseph, 2004, "Renewed land debate and the 'cargo cult' in Mozambique", Journal of Southern African Studies, 30 (3): 603-625.

HUHN, Arianna, 2013, "Sustenance and sociality: foodways in a Mozambican town". Boston: Graduate School of Arts and Siences, Boston University, tese de doutoramento.

INE - INSTITUTO NACIONAL DE ESTATÍSTICA, 2019, Dados do Recenseamento Geral da População de 2019. Consultado em < http://www.ine.gov.mz > (última consulta em dezembro de 2020).

JOHNSON, William Percival, 1922, Nyasa the Great Water: Being a Description of the Lake and the Life of the People. Westminster: UMCA.

LENTZ, Carola, 2006, "First-comers and late-comers: indigenous theories of land ownership in the West African savannah", in Richard Kuba e Carola Lentz (orgs.), Land and the Politics of Belonging in West Africa. Leiden: Brill, 35-56.

LENTZ, Carola, 2010, "Is land inalienable? Historical and current debates on land transfers in northern Ghana", Africa: The Journal of the International African Institute, 53 (1): 56-80.

LENTZ, Carola, 2013, Land, Mobility and Belonging in West Africa. Bloomington e Indianapolis: Indiana University Press.

LIESEGANG, Gerhard, 1984, "Guerras, terras e tipos de povoações: sobre uma 'tradição urbanística' do norte de Moçambique no século XIX", Revista Internacional de Estudos Africanos, 2 (1): 169-184.

MACPHERSON, Crawford B., 1992 [1972], "The meaning of property", in Crawford B. MacPherson (org.), Property: Mainstream and Critical Positions. Toronto e Buffalo: University of Toronto Press, 1-13. 
MAMDANI, Mahmood, 1996, Citizen and Subject: Contemporary Africa and the Legacy of Late Colonialism. Princeton: Princeton University Press.

MANDAMULE, Uaciticissa, 2017, “Tipologia dos conflitos sobre ocupação da terra em Moçambique", in Uacitissa Mandamule (org.), Terra, Poder e Desenvolvimento em Moçambique. Maputo: Escolar Editora, 201-237.

MARWICK, Max, 1952, "The kinship basis of cewa social structure”, South African Journal of Science, 48 (8): 258-262.

MAZULA, Assahel J., 1962, "História dos Nianjas", Revista de Cultura Missionária, 19: 154$-167$.

MEDEIROS, Eduardo, 2006, "Dos territórios linhageiros aos regulados coloniais no vale do Lúrio e na circunscrição de Montepuez durante e após a Companhia do Niassa: Notas exploratórias para uma análise antropológica da cartografia", Africana Studia, 9: 269$-298$.

MENESES, Maria Paula, 2009, “Poderes, direitos e cidadania: O 'retorno' das autoridades tradicionais em Moçambique”, Revista Crítica de Ciências Sociais, 87: 9-42.

MINAG - MINISTÉRIO DA AGRICULTURA, 2010, Relatório de Trabalho de Campo Realizado no Âmbito do Cumprimento das Decisões de S. Excia o Senhor Primeiro Ministro na Sua Visita à Província do Niassa. Maputo: Ministério da Agricultura.

MITCHELl, J. Clyde, 1956, The Yao Village: a Study in the Social Structure of a Nyasaland Tribe. Manchester: Manchester University Press.

MOSCA, João, 201 1, Políticas Agrárias de (em) Moçambique (1975-2009). Maputo: Escolar Editora.

MYERS, Gregory, 1994, "Competitive rights, competitive claims: land access in post-war Mozambique”, Journal of Southern African Studies, 20 (4): 603-632.

NEGRÃO, José, 2002, "Sistemas costumeiros da terra", in Boaventura de Sousa Santos e João Carlos Trindade (orgs.), Conflito e Transformação Social: Uma Paisagem das Justiças em Moçambique. Porto: Afrontamento, 229-257.

NEGRÃO, José, 2008, Repensando a Terra e as Modas do Desenvolvimento Rural. Maputo: Texto Editores.

ORAM, 2010, Estudo sobre Conflito de Interesses na Gestão e Exploração da Terra em Moçambique: Os Casos dos Distritos de Massinga, Zavala, Macomia e Mecufi. Maputo: ORAM.

PETERS, Pauline E., 2009, "Challenges in land tenure and land reform in Africa: anthropological contributions”, World Development, 37 (8): 1317-1325.

PINA-CABRAL, João de, 1991, Os Contextos da Antropologia. Lisboa: Difel.

POTIER, Johan, 2005, “'Customary land tenure' in Sub-Saharian Africa today: meanings and contexts", in Chris Higgins e Jenny Clover, From the Ground Up: Land Rights, Conflict and Peace in Sub-Saharian Africa. Pretoria: Institute for Security Studies, 55-76.

RANGER, Terence, 1993, "The communal areas of Zimbabwe”, in Thomas Basset e Donald Crummey (orgs.), Land in African Agrarian Systems. Madison: University of Wisconsin Press, 354:385.

RIVAL, Laura, 2002, Trekking Through History: the Huaorani of Amazonian Ecuador. Nova Iorque: Columbia University Press.

SERRA, Carlos M., e João CARRILHO (orgs.), 2013, Dinâmicas da Ocupação e do Uso da Terra em Moçambique. Maputo: Escolar Editora.

STRATHERN, Marilyn, 2009, "Land: intangible or tangible property?", in Timothy Chesters (org.), Land Rights. Oxford: Oxford University Press, 13-38. 
TANNER, Christopher, 2002, "Law-making in an African context: the 1997 Mozambican land law", FAO legal papers online \#26. Disponível em < http://www.fao.org/3/a-bb059e .pdf > (última consulta em dezembro de 2021).

TURNER, Victor W., 1957, Schism and Continuity in an African Society: a Study of Ndembu Village Life. Manchester: Manchester University Press.

VAN VELSEN, Jaap, 1971 [1964], The Politics of Kinship: a Study in Social Manipulation Among the Lakeside Tonga of Malawi. Manchester: Manchester University Press.

VIEGAS, Susana de Matos, 2007, Terra Calada: os Tupinambá na Mata Atlântica do Sul da Bahia. Coimbra: Almedina.

WEST, Harry, 1992, Local-Level Political Legitimacy and Security of Land Tenure in Mozambique. Madison: Land Tenure Center University of Wisconsin.

WEST, Harry, e Gregory W. MYERS, 1992, Local-Level Political Legitimacy and Security of Land Tenure in Mozambique. Madison: Land Tenure Center University of Wisconsin.

WEST, Harry, e Gregory W. MYERS, 1996, "A piece of land in a land of peace? State farm divestiture in Mozambique", The Journal of Modern African Studies, 34 (1): 27-51.

WUYTS, Mark, 2001, “The agrarian question in Mozambique’s transition and reconstruction”, Discussion Paper 14, United Nations University.

Receção da versão original / Original version

$2019 / 10 / 29$

Aceitação / Accepted

$2020 / 09 / 04$

Pré-publicação online / Pre-published online

$2022 / 01 / 24$ 